\title{
Scour monitoring on bridge pier - methodology and implementation
}

\author{
Emma Florens ${ }^{1}$, Christophe Chevalier ${ }^{2}$, Frédérique Larrarte ${ }^{3}$, Franziska Schmidt $^{2}$, and \\ Edouard Durand ${ }^{4}$ \\ ${ }^{1}$ IRT Railenium, 180 rue Joseph-Louis Lagrange 59540 Valenciennes - France \\ ${ }^{2}$ IFSTTAR/GERS/SRO and MAST/EMGCU, 14-20 bd Newton - Champs s/ Marne 77447 Marne-la- \\ Vallée cedex 2 - France \\ ${ }^{3}$ IFSTTAR/GERS/LEE, Rte de Bouaye CS4 44344 Bouguenais cedex - France \\ ${ }^{4}$ Cerema, 11 rue Laplace - CS 32912 - F-41029 Blois - France
}

\begin{abstract}
Managing the scour risk of civil structures such as bridge piers, constitutes a major challenge to sustainable development and land use planning. The SSHEAR project aims to build optimized diagnostic, warning and management methods to benefit civil structures. This article is focused on the "Field" approach of the project that develop continuous and real-time scour monitoring. Based on theoretical approach and river database analysis, requirement specifications definition allowed to choose relevant devices to monitor scour. To complete this monitoring system, vibration-based monitoring will also be installed.
\end{abstract}

\section{Background and issues}

In rail or road transportation infrastructure system, bridge maintenance represents a high operating cost. Because of their ability to connect territories and populations, any failure can have significant financial, human and social impact. In most configurations, bridges are across rivers. This flow/structure interaction leads to scouring process that represents a significant contributing factor in the deterioration of structures and could lead to collapse. For example, the French railway network includes 1,700 river-crossing structures [1]. In the case of road infrastructure, more than 2000 road bridges crossing rivers have been identified as scour vulnerable just for the principal road network of the French department Gard [2].

Today, significant research actions are made by US laboratory and transportation organizations, far less by French ones. Indeed, an ongoing scour evaluation program, leaded by the Federal Highway Administration and state highway agencies, identified about 17,000 scour critical bridges around the country [3]. Across the US, $60 \%$ of reported bridge failures are due to scour, about 20,000 bridges are as "scour critical" and the same number as "scour susceptible" [4].

With this background, many monitoring systems have been developed, based on intrusive or non-intrusive devices, as time domain reflectometry or vibration based devices. Many articles have made their reviews and tested their sensibility to their environment [4-6]. Most 
of them are alert system, such as low-cost sonar or magnetic sliding collar devices, which are mostly implemented by the US highway agencies [3].

But all these monitoring systems focus only on the bathymetry aspect of the scour problem, without correlating it to the flow conditions. However, the entire scour community agrees that the main cause of scour is high flow conditions. Indeed, lot of laboratory experiments are conducted to link flow structure and scour dynamic. Difficulties in applying similitude laws both for scour and flow parameters have made their results not enough transposable to field conditions. To our knowledge, there is a real lack in flow and bathymetry field experiments.

Financed by the French Research Agency (ANR), the SSHEAR project, "Soils, $\underline{\text { Structures }}$ and Hydraulics: Expertise and Applied Research", has been set up to improve scour mechanisms knowledge, to develop innovative experimental and observational tools and hydraulic numerical models at both laboratory [7] and full-scale, and then to build optimized diagnostic, warning and management methods for bridges operators. Physical and numerical progress in both sedimentary hydrodynamics and soil mechanics allow to consider a comprehensive study characterizing the scour hazard by means of innovative instrumentation based on the recent improvements in acoustic technics for bathymetry and flow and in vibrations measurements [8].

The "field approach" task of SSHEAR project seeks to develop tools and a methodology expected to lead to an improved characterization and monitoring of sites with regards to the problem of structural scouring. The first step has been to identify pilot sites, representative of scour vulnerability [1]. The aim is to equip these pilot sites with a bedform "scour" monitoring system to better characterize the susceptibility of in-situ sediment to erosion. It will consist in several sensors installed adjacent to or on the structures to measure and track continuously the scour parameters, both hydraulic and bathymetric. Monitoring devices will be left in place for a full year. Database statistical analysis will then allow to assess the flow ability to favor or disadvantage pier scour. Depending on the analysis results, it will possible to propose a new method for scour monitoring, with or without field sensors (i.e. only with public river database).

In this article, the theoretical background which permits us to define the scour parameters to be monitored, will be first presented. Then, the benchmark study and the choice of monitoring devices available on the market will be detailed. Instrumentation, sensor adaptability, limitations (actual measurement ranges, plus ergonomics, energy supply limits) and in situ implementation will be presented and discussed in this section. Finally, the posttreatments intended on the database to be will be discussed as the perspectives of SSHEAR project field part.

\section{Theoretical approach}

Scour phenomenon is a complex combination of several processes, and can be defined as "the excavation and removal of the material from the bed and banks of stream as a result of the erosive action of flowing water" [5]. It can be classified into 3 types:

- General Scour is commonly called sediment transport and occurs all along the river bed because of the change in flow conditions [9].

- Contraction scour is due to the reduction in the cross-sectional area of the river bed typically at the location of a bridge. In this configuration, the section contraction increases the flow velocity and consequently the bed shear stress [10].

- Local scour is also the consequence of bridge presence but here, it occurs around obstacles like piers. The pier creates coherent flow structures, like horseshoe and 
wake vortices, in its vicinity which change locally the shear stress and create scour (see Fig. 2 (Left), from [5]).
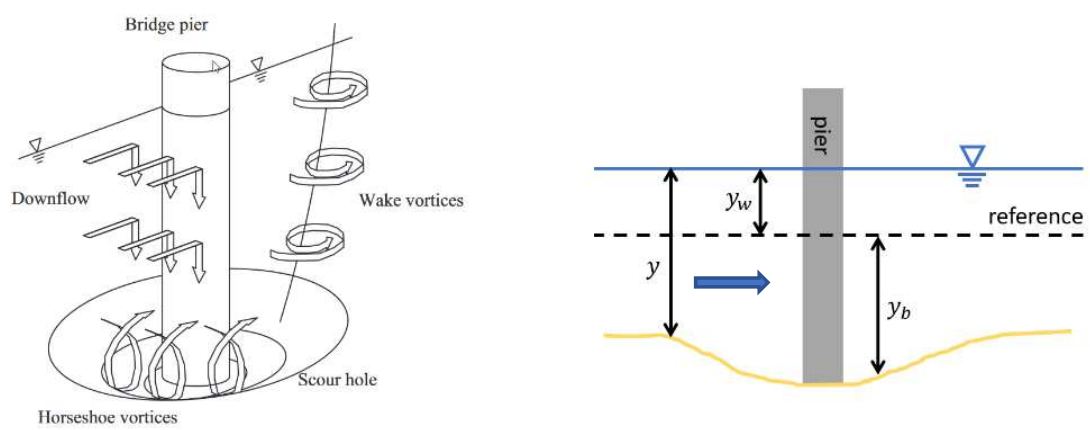

Fig. 1. (Left) Scour process sketch [5], (Right) Schematic definition of water depth $y$, water surface elevation $y_{w}$ and bathymetry $y_{b}$. (Blue arrow: flow direction)

It is widely admitted that all the processes are related to the flow conditions, the pier/bridge geometry, the bed sediment properties, and most of these parameters are known to be dynamic. The depth of a local scour is then a complex function, which can be written as [11]:

where:

$$
y_{b}=f\left[(\rho, v, V, y, g),\left(d_{50}, \sigma_{g}, \rho_{s}, V_{c}\right),(b, S h, A l),\left(t, t_{e}\right)\right]
$$

- $(\rho, v, V, y, g)$ are the river flow parameters, respectively the fluid density, the kinematic viscosity, the mean approach flow velocity, the mean approach flow depth and the acceleration of gravity,

- $\left(d_{50}, \sigma_{g}, \rho_{s}, V_{c}\right)$ are the bed sediment parameters, respectively the median size distribution of the sediment particle, the geometric standard deviation of the size distribution, the sediment density, and the critical mean approach flow velocity for entrainment of bed sediment,

- $(b, S h, A l)$ are the bridge geometry parameters, respectively the width, the shape and the alignment parameters of the pier,

- $\left(t, t_{e}\right)$ are the temporal parameters, respectively the time, and the time for the equilibrium depth of scour to be reached.

According to Eq. 1, the parameters which must be monitored appear to be the "more dynamic" ones. Considering the weak variations of $\rho$ and $v$ with temperature, these parameters are the flow depth $y$ and the flow velocity $V$, and, linked to it, the critical velocity of entrainment $V_{c}$. In fact, it is not directly the flow velocity $V$, but its ability to erode the river bottom, that must be estimated, which is characterized by the critical velocity of entrainment $V_{c}$.

As it was mentioned in the previous section, the scour dynamic is very sensitive to bed shear stress variations. In river flows, shear stress is exclusively due to turbulence. In a fully turbulent developed flow, the turbulent shear stress increases linearly when approaching the bottom. The bed shear stress is then very dependent with flow conditions.

The bed shear stress is involved in the calculation of the critical velocity [12]:

$$
V_{c}=\frac{u_{*} C}{\sqrt{g}}, \quad \text { with } \quad u_{*}=\sqrt{\frac{\tau_{0}}{\rho}}
$$


with $u_{*}$ is the friction velocity, linked to the bed shear stress $\tau_{0}$ according to Eq. 2 , and $C$ is a Chezy-type coefficient based on river bed rugosity and its hydraulic radius [12]. Then it is possible to access the bed shear stress thought the friction velocity $u_{*}$, assuming a uniform and stationary flow at the place and during the measurement:

- Either using the velocity profile, in the log-law zone, $u_{*}$ can be estimated by fitting the profile with a logarithmic plot [13]. This is the most common and used technique.

- Or using the turbulent shear stresses, the extrapolation of the linear total shear stress profile to the bed position gives a good estimation of its value, and it is the most direct way to estimate this parameter [14].

To access the water depth $y$, simultaneous measurements can be made on water surface elevation $y_{w}$ and bathymetry $y_{b}$ (see Fig. 2 (Right)) which are linked with water depth by the equation:

$$
y=y_{b}+y_{w}
$$

\section{Monitoring system}

\subsection{Sites description}

During the first phase of the SSHEAR project, several criteria were defined to select the sites that would be monitored during a brief campaign and for some longer continuous periods. These criteria were related to:

- bridge vulnerability to scour,

- bridge geometry (type of bridge and its representativeness, type of piers, ...),

- river conditions (flow conditions, hydro-morphology, nature of sediment...),

- geology and geotechnical parameters (foundations type, bedrock or reinforcement presence...),

- the site accessibility.

A rather exhaustive classification of their bridges has been done by the networks operators participating to the SSHEAR project, using GIS and managing tools and databases. Then a short list was made and, after a second step of selection, 2 sites have been chosen [1].

The Loire-A71 bridge (Fig. 2 (Left)) is a double viaduct. It is representative of structures crossing main rivers in the oceanic part of France. The two decks rests on 6 supports, each one composed by 1 or 2 piers, established into the floodplain. 4 supports are set up in river bed. For this bridge, local scour was observed around 2 supports, $n^{\circ} 3$ and 4 (Fig. 3). One of these two scour holes will be monitored in real time over one year.
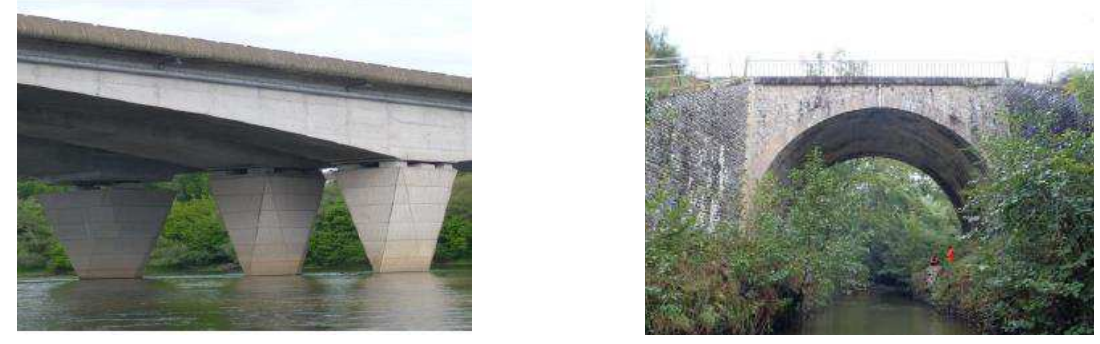

Fig. 2. (Left) Investigated site on the A71 motorway double viaduct next to Orléans (France) over Loire river (one support with its 3 piers). (Right) Railway bridge, investigated site over the Aurence River close to Limoges (France). 
It must be noted that Loire river is the widest (200 $\mathrm{m}$ of mean width) and the longest one (about $1000 \mathrm{~km}$ long) in France, with a mean flow rate of $931 \mathrm{~m}^{3} / \mathrm{s}$.

Close to the piers, the water depth can vary seasonally from $40 \mathrm{~cm}$ to $5 \mathrm{~m}$ and the flow velocity was estimated from 0.5 to $2.5 \mathrm{~m} / \mathrm{s}$.

The Aurence bridge (Fig.2 (Right)) is a railway single arch structure. This kind of structure is very common on the secondary railway network but also on the country side roads. In this case, contraction scour was observed and will be real-time monitored continuously over a year.

Unlike the Loire, the Aurence is a very small river, with a mean width of $5 \mathrm{~m}$ of and less than $30 \mathrm{~km}$ long, with a mean flow rate of $1.22 \mathrm{~m}^{3} / \mathrm{s}$. The mean water depth is quietly constant, about $35 \mathrm{~cm}$ near the chosen bridge, but it is very sensitive to rain and can increase to more than $1 \mathrm{~m}$. The flow velocity range is about 0.2 to $1.5 \mathrm{~m} / \mathrm{s}$.

About the bathymetry, analysis of former measurements, made regularly (in 2004, 2011, 2016), on Loire site revealed a scour cycle. Between 2004 and 2011, results showed a degradation of the river bed around the piers, while it showed deposition between 2011 and 2016 (see Fig. 4).

The data analysis for the Aurence site is still in progress when this article was written.

These 2 sites offer various flow and scour conditions. After analyzing their flow and bathymetry conditions, some requirement specifications were formulated to find devices available on the market.
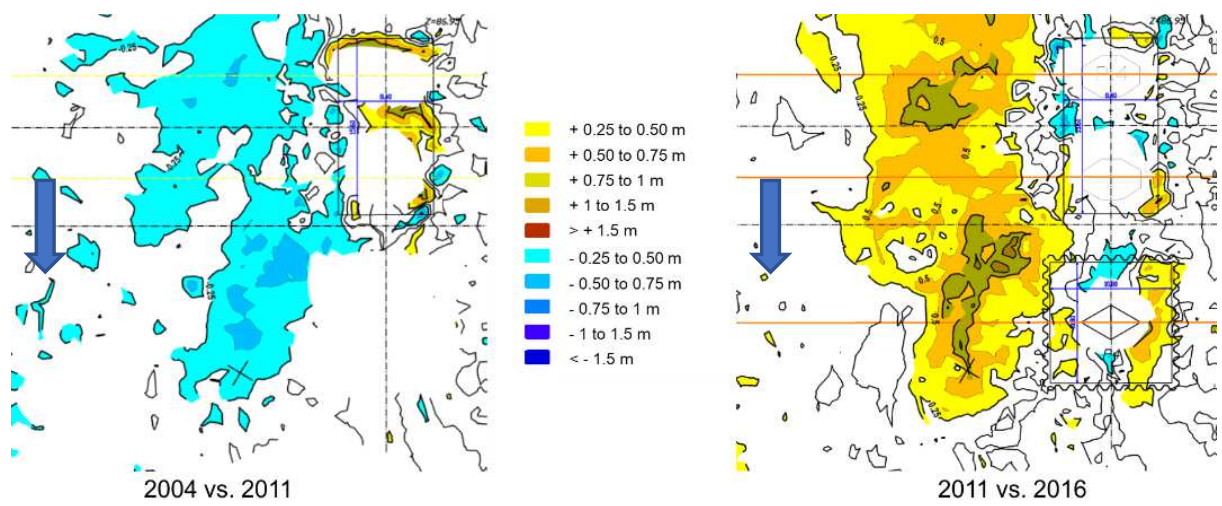

Fig. 3. Results of comparison between 3 bathymetry campaigns (2004, 2011 and 2016) near the pier 4 of the A71 highway viaduct over the Loire river. (Blue arrow: flow direction)

\subsection{Monitoring systems benchmark study}

The study of flow conditions and bathymetry situation of the two sites that has been described previously made it possible to have velocity and water depth ranges, and was the basis of requirement specifications list to make a benchmark study of the devices available for the real-time monitoring system.

During the benchmark study, the devices were evaluated on two kinds of requirements: their ability to real-time monitoring and their ability to measure in a relevant way in field conditions. These aspects are discussed in this section.

The first requirements are linked to the field deployment and the real-time aspect: system autonomy and wireless data transmission, possibility for the user to calibrate measurement parameters without being near the system. Some specifications about 
acquisition were made to expect relevant values of the scour parameters identified previously. There are registered in Table 1.

Table 1. Control specifications

\begin{tabular}{|c|c|}
\hline Parameter & Specification \\
\hline $\begin{array}{l}\text { Acquisition } \\
\text { frequency }\end{array}$ & $\begin{array}{l}\text { Every } 30 \text { minutes: } \\
\text { - A value of water and bathymetry elevation } \\
\text { - At least } 1000 \text { instantaneous velocity profiles at } 1 \mathrm{~Hz} \text { minimum. } \\
\text { Specifications about velocity measurements will allow to have a well } \\
\text { converged velocity profile [13]. } \\
\text { The velocity profiles will be time-averaged after the acquisition. } \\
\text { The frequency can be change by the user based on the continuous } \\
\text { analysis of the database. }\end{array}$ \\
\hline $\begin{array}{l}\text { Mechanical } \\
\text { integration }\end{array}$ & $\begin{array}{l}\text { Minimal intrusion: on the free surface or on the bridge, not on the river } \\
\text { bottom to avoid local scour around the system. }\end{array}$ \\
\hline Acquisition & $\begin{array}{ll}\text { - } & \text { Automatic data recovery } \\
\text { - } & \text { Parametrizable pretreatment of outliers } \\
\text { - } & 4 \mathrm{G} \text { transmission to a website or a data server }\end{array}$ \\
\hline Power Supply & Autonomous (only for Aurence site) \\
\hline Supervision & System integrity control with a camera and a web server \\
\hline
\end{tabular}

Table 2. Requirement specifications for the Loire site

\begin{tabular}{|c|c|c|c|c|c|}
\hline $\begin{array}{c}\text { Scour } \\
\text { parameter }\end{array}$ & \multicolumn{4}{|c|}{ Specifications } & Remarks \\
\hline \multirow[b]{2}{*}{$V, u_{*}$} & Range & Res & ion & Precision & \multirow{2}{*}{$\begin{array}{l}\text { Resolution: distance between } 2 \\
\text { points in the vertical profile. } \\
\text { Need to measure turbulence close } \\
\text { to the river bottom. }\end{array}$} \\
\hline & $\begin{array}{c}0.5 \text { to } 2.5 \\
\mathrm{~m} / \mathrm{s}\end{array}$ & \multicolumn{2}{|c|}{$1-5 \mathrm{~cm}$} & $\begin{array}{c}+/-1 \% \max \\
(0.01 \mathrm{~m} / \mathrm{s})\end{array}$ & \\
\hline \multirow[b]{2}{*}{$y_{w}$} & \multicolumn{2}{|c|}{ Range } & & Precision & \multirow{2}{*}{$\begin{array}{l}\text { The range can depend on where the } \\
\text { device is fixed. }\end{array}$} \\
\hline & \multicolumn{2}{|c|}{0.3 to $5 \mathrm{~m}$} & & $+/-1 \mathrm{~cm}$ & \\
\hline \multirow[b]{2}{*}{$y_{b}$} & \multicolumn{2}{|c|}{ Range } & & easured zone & \multirow{2}{*}{$\begin{array}{l}\text { - As for water surface elevation } y_{w} \text {, } \\
\text { the range can depend on where the } \\
\text { device is fixed } \\
\text { - Precision will be dependent of the } \\
\text { device, see next section. }\end{array}$} \\
\hline & \multicolumn{2}{|c|}{0.3 to $5 \mathrm{~m}$} & \multicolumn{2}{|r|}{ About $2 \times 2 \mathrm{~m}^{2}$} & \\
\hline
\end{tabular}

Table 3. Requirement specifications for Aurence site

\begin{tabular}{|c|c|c|c|c|}
\hline $\begin{array}{c}\text { Scour } \\
\text { narametter }\end{array}$ & \multicolumn{3}{|c|}{ Specifications } & Remarks \\
\hline \multirow[b]{2}{*}{$V, u_{*}$} & Range & Resolution & Precision & \multirow{2}{*}{$\begin{array}{l}\text { - Resolution: distance between } \\
2 \text { points in the vertical profile. } \\
\text { - } \quad \text { Need to measure turbulence } \\
\text { closed to the river bottom. }\end{array}$} \\
\hline & $\begin{array}{c}0.2 \text { to } 1.5 \\
\mathrm{~m} / \mathrm{s}\end{array}$ & $1-5 \mathrm{~cm}$ & $\begin{array}{c}+/-1 \% \max \\
(0.01 \mathrm{~m} / \mathrm{s})\end{array}$ & \\
\hline \multirow{2}{*}{$y_{w}$} & \multicolumn{2}{|c|}{ Range } & Precision & \multirow{2}{*}{$\begin{array}{l}\text { The range can depend on where the } \\
\text { device is fixed }\end{array}$} \\
\hline & 0.2 to 1 & & $-0.1 \mathrm{~cm}$ & \\
\hline$y_{b}$ & \multicolumn{4}{|c|}{ (Data analysis in progress) } \\
\hline
\end{tabular}


In Tables 2 and 3, the scour parameters requirement specifications are detailed, respectively for the Loire site and the Aurence site. Based on the range evaluated for velocity and water elevation, measurement precision and resolution are detailed for both sites.

\subsection{SSHEAR monitoring system}

After auditioning several suppliers, the device choice was made for most of the monitoring system. The details are given in this section.

\subsubsection{Velocity measurements}

For the Loire site, the choice has not been made yet because of the specification obligation: the velocity profiles must be measured in the log-law zone to obtain the friction velocity $u_{*}$. Considering the water depth, the first considered devices were doppler acoustic profilers, but the relevance of measured values near to the river bottom is not sufficient.

For the Aurence site, the velocity profile will be measured with an ultrasonic velocity profiler UBFlow. This device has been used previously in sewer network study to measure both the flow velocity and the water depth [15].

\subsubsection{Water surface elevation measurements}

For both investigated sites, the water surface elevations will be measured with a radar level sensor. A VRS-20 Valeport pulsed k-band radar level sensor has been recently acquired and will be installed soon on river Loire A71 site. Its precision is $1 \mathrm{~mm}$, its accuracy $10 \mathrm{~mm}$ and its minimum and maximum ranges are $0,8 \mathrm{~m}$ and $20 \mathrm{~m}$, respectively.

\subsubsection{Bathymetry measurements}

For the Loire site, the bathymetry will be measured using a Dual-Axis Sonar, which has as outputs an X, Y, Z serial data string of profile points. To have a constant spatial resolution whatever the water depth, the sonar will be fixed on the closest pier by steel arms just upward the zone with the most important sedimentary dynamics. A spatial resolution of about $1 \mathrm{~cm}$ is expected.

For Aurence site, the data analysis of former bathymetry measurements is expected before choosing any devices.

\subsubsection{Vibration measurements}

As it was mentioned in the first section, vibration measurements are commonly used in scour monitoring to give alert information. In this case, the flow and bathymetry measurements will be coupled with vibration measurements made with accelerometers.

Vibration monitoring, from the bridge/bridge pier itself [16] or from added devices [17], is a well-documented method for bridge scour monitoring. Some recent works have been devoted to the better understanding of the physical mechanisms of soil-structure interaction of the bridge pier and its modelling [18].

For the second site (Aurence river), the monitoring procedure is not defined up to now, as the structure is of masonry type. But on Loire river, where the bridge under interest is a prestressed concrete bridge, the accelerations in the direction of the water flow will be monitored, with a seismic accelerometer (sensitivity: $1 \mathrm{~V} / \mathrm{g}$, frequency range: 0.06 to $450 \mathrm{~Hz}$ ). 


\section{Future work and final goal}

To fill gaps in scour knowledge, the SSHEAR project brings together expert knowledge of different fields to improve the analysis of bridge vulnerability to scour.

A rigorous process, ranging from state of art to devices choice, resulted in the development of a real-time monitoring system.

Once device choice is complete, each sensor but also the entire system will be tested in laboratory and in field before being permanently deployed.

Then, this system will work for a full year to build a database, whose analysis will hopefully highlight correlations between flow conditions and scour dynamic. Its implementation is also an opportunity to test the possibility for an infrastructure manager to simply implement a monitoring system.

The present work benefits from the financial support of the ANR French Research Agency within the project SSHEAR ANR-2014-CE03-0011.

\section{References}

1. B. Salavati, M. Cheetham, L. Mella, A. Siduron, C. Pams Capoccioni, GEORAIL (2017)

2. J.-P. Naulin, O. Payrastre, E. Gaume, J. Hydrology, 486, 88 (2013)

3. J.D. Schall, P. Davies, TR News 203 (July-August 1999)

4. M. Fisher, M. Chowdhury, A. Khan, S. Atamturktur, Flow Meas. Instrum., 33, 55 (2013)

5. L.J. Prendergast, K. Gavin, J. Rock Mech. Geotech. Eng. 6, 138 (2014)

6. L. Deng, C.S. Cai, Pract. Period. Struct. Des. Constr., 15(2), 125 (2010)

7. F. Lachaussée, Y. Bertho, C. Morize, A. Sauret, P. Gondret, Phys. Rev. Fluids 3 (2018)

8. C. Chevalier, F. Larrarte, F. Schmidt, D. Pham-Van-Bang, E. Durand, P. Gondret, S. de la Roque, M. Cheetham, M. Hosseingholian, ICSMGE-19 (Sept. 2017)

9. M.C. Forde, D.M. McCann, M.R. Clark, K.J. Broughton, P.J. Fenning, A. Brown, NDT\&E International, 32(8), 481 (1999)

10. J. L. Briaud, F. Ting, H.C. Chen, R. Gudavalli, K. Kwak, B. Philogene, ..., Y. Cao, Texas Transportation Institute Texas USA, Report, (1999)

11. R. Ettema, B.W. Melville, B. Barkdoll, J. of Hyd. Eng. 124(6), 639 (1998)

12. G. J. Hoffmans, H. J. Verheij, CRC press (1997)

13. E. Florens, PhD Thesis, Université de Toulouse (2010)

14. O. Eiff, E. Florens, F. Moulin, River Flow-7 (Nov. 2014)

15. N. Hemmerle, J.J. Randrianarimanana, C. Joannis, F. Larrarte, Int. Symp. on Ultrasonic Doppler Methods for Fluid Mech. and Fluid Eng.-9 (Aug. 2014)

16. T. Bao, R. Swartz, S. Vitton, Y. Sun, C. Zhang, Z. Liu, J. Sound Vib. 386, 116 (2017)

17. A. Zarafshan, A. Iranmanesh, F. Ansari, F., J. Bridge Eng. 17(6), 829 (2012)

18. N. Boujia, F. Schmidt, D. Siegert, D. Pham Van Bang, C. Chevalier, Procedia Eng. 199, 2925 (2017) 